\title{
ORIGINAL
}

\section{Distinct metabolic effects following short-term exposure of different high-fat diets in male and female mice}

\author{
Shiva PD Senthil Kumar ${ }^{1 *}$, Minqian Shen ${ }^{1)^{*}}$, Elizabeth G Spicer ${ }^{2)}$, Ashley J Goudjo-Ako ${ }^{3)}$, Justin D Stumph ${ }^{3)}$, \\ Jing Zhang ${ }^{4)}$ and Haifei Shi ${ }^{1), 3)}$ \\ 1) Cell, Molecular, and Structural Biology, Miami University, Ohio, 45056, United States \\ 2) Department of Nursing, School of Engineering and Applied Sciences, Miami University, Ohio, 45056, United States \\ 3) Program in Physiology and Neuroscience, Department of Biology, Miami University, Ohio, 45056, United States \\ 4) Department of Statistics, Miami University, Ohio, 45056, United States
}

\begin{abstract}
Obesity-associated hepatic lipid accumulation and chronic low-grade inflammation lead to metabolic defects. Saturated fatty acids (SFA) are a risk factor for, whereas unsaturated fatty acids (UFA) are thought to be protective against, developing metabolic diseases. Sex differences exist in the regulation of metabolism. We tested the hypothesis that diets high in SFA, mono-UFA (MUFA), or poly-UFA (PUFA) had early, sex-distinct effects that differentially contribute to longterm metabolic disturbance such as fatty liver and insulin resistance. Metabolic changes including body and fat mass, circulating leptin and glucose levels, plasma lipid profile, hepatic lipid accumulation, expression levels of genes related to lipid metabolism and low-grade inflammation, and tissue insulin sensitivity were compared between male and female mice fed with a low-fat chow, or high-fat SFA, MUFA, or PUFA for a short period of four days. SFA and MUFA males increased adiposity associated with increased liver lipid accumulation and rapid activation of inflammation in adipose and muscle tissues, whereas PUFA males did not show lipid accumulation or tissue inflammation compared to chow males. All SFA and UFA males displayed tissue insulin resistance. In contrast, female high-fat diet groups had normal liver lipid content and maintained tissue insulin sensitivity without showing tissue inflammation. Therefore, sex differences existed during early phase of development of metabolic dysfunction. The beneficial effects of PUFA, but not MUFA, were corroborated in protection of obesity, hyperlipidemia, fatty liver, and low-grade inflammation. The benefit of MUFA and PUFA in maintaining tissue insulin sensitivity in males, however, was questioned.
\end{abstract}

Key words: Sex difference, De novo lipogenesis, $\beta$-oxidation, Insulin sensitivity, Low-grade inflammation

HIGH-FAT CONTENT in typical Western diets is an important factor leading to obesity and related dyslipidemia, fatty liver, cardiovascular diseases (CVD), and insulin resistance [1,2], although the link between these metabolic diseases is not completely understood. Some relatively lean individuals are insulin resistant whereas some obese individuals are not [3]. Rosiglitazone, an insulin sensitizer, improves insulin sensitivity but increases adiposity at the same time in rodents and humans [4-6]. Defects in lipid metabolism associated

Submitted Oct. 30, 2013; Accepted Jan. 27, 2014 as EJ13-0455 Released online in J-STAGE as advance publication Mar.20, 2014 Correspondence to: Haifei Shi, Department of Biology, Miami University, 700 E High St., Oxford, Ohio, 45056, United States. E-mail: shih@miamioh.edu

*Shiva PD Senthil Kumar and Minqian Shen contributed equally to this study.

Abbreviations: Acc, acetyl Co-A carboxylase; CVD, cardiovascu- with obesity, such as lipid overload that increases circulating free fatty acids (FFA) [7], ectopic hepatic lipid accumulation $[8,9]$, and low-grade inflammation activated by macrophages of white adipose tissue (WAT) $[10,11]$, rather than adiposity per se, are key factors for developing metabolic dysfunctions. Lipid accumulation and insulin resistance in WAT and liver occur three days after high-fat diet (HFD) feeding, prior to development of insulin resistance in skeletal muscle [12]. Short-term HFD feeding also induces tissue inflamma-

lar diseases; Fas, fatty acid synthase; FFA, free fatty acids; HDL-C, high density lipoprotein-cholesterol; HFD, high-fat diet; HPV, hepatic portal vein; LDL-C, low density lipoprotein-cholesterol; Mcp-1, monocyte chemoattractant protein-1; MUFA, monounsaturated fatty acids; Pgc1 $\alpha$, peroxisome proliferator-activated receptor gamma coactivator 1- $\alpha$; PUFA, polyunsaturated fatty acid; SFA, saturated fatty acids; Srebp-1c, sterol regulatory binding protein1c; TG, triglycerides; WAT, white adipose tissue 
tion in WAT three days after HFD feeding [13], and in skeletal muscle and liver seven days after HFD feeding [14]. These studies suggest that dietary fat rapidly induces lipid storage, inflammation, and insulin resistance at metabolic tissues.

Although the association between dietary fat and incidence of metabolic diseases has been recognized, relative contribution of different types of fat to metabolic defects is not clear. Most of studies have focused upon lard, a major constituent of fat for average Western diet, lacking comparison of animals consuming similar percentage of calories from other types of fat. Lard contains a predominance of SFA, a fat type implicated as risk for progression of metabolic diseases [15]. Some fat sources are reputed to be less harmful and may be beneficial. There is evidence linking diets high in MUFA [16, 17] and PUFA [18-21] to be less lipogenic and protective against obesity, with lower risk for diabetes and fatty liver, as compared with diets high in SFA.

Sex differences exist in regulating glucose and lipid metabolism. Women compared with men with matched adiposity generally have less visceral distribution of fat and lower susceptibility to insulin resistance [22-24]. In order to develop gender appropriate therapies for treating metabolic disorders, there is a need for understanding progression of these metabolic diseases in both males and females. However, most metabolic studies have been done using male subjects only. There has been no study that evaluates roles of different HFDs rich in SFA, MUFA, or PUFA in sexspecific regulation of metabolism.

We hypothesized that diets high in SFA, MUFA, or PUFA had early, sex-distinct effects that differentially contribute to long-term metabolic dysfunction such as fatty liver and insulin resistance. We also clarified whether HFD-induced rapid changes in lipid overload, ectopic lipid accumulation, and/or inflammation contributed to induction of insulin resistance. To understand sex differences in effects of dietary fat on metabolism, metabolic changes including body mass and fat mass, circulating leptin and glucose levels, plasma lipid profile, hepatic lipid accumulation, expression levels of genes related to lipid metabolism and low-grade inflammation, and tissue insulin sensitivity were compared among male and female mice fed with a low-fat chow, or one of three HFDs with identical calories, nutrient contents, and matched total fat, but rich in different types of lipids, i.e., lard-based HFD with SFA, olive oil- based HFD with MUFA, and menhaden oil-based HFD with PUFA, for a short period of four days.

\section{Materials and Methods}

\section{Animals and diets}

Male and female twelve weeks-old C57BL/6 mice ( $\mathrm{n}=8-9$; Jackson Laboratory, Bar Harbor, ME) were housed in separate rooms with a $12 \mathrm{~h}$ light-dark cycle (lights on at 0600). Mice were fed a standard low-fat chow (Harlan-Teklad, Madison, WI) during acclimation when their body mass and food intake were monitored, and ovarian cycles of female mice were tracked. Daily food intake of each mouse was calculated individually by the difference of food weights over 24 hours and corrected for spillage. Food intake data were then converted to calories. After acclimation, mice were grouped into four groups for each sex with matched average body mass and daily caloric intake. Mice were then fed daily with equal amount of calories of either the low-fat chow $(3.003 \mathrm{kcal} / \mathrm{g} ; 14 \%$ calories from fat) or one of three HFDs $(4.728 \mathrm{kcal} / \mathrm{g} ; 45 \% \mathrm{cal}-$ ories from fat; Research Diets, Inc., New Brunswick, NJ): lard with SFA (palmitic acid C16:0; stearic acid C18:0), olive oil with MUFA (oleic acid 18:1, N-9), or menhaden oil with PUFA (eocosapentaenoic acid 20:5, $\mathrm{N}-3$; docosahexaenoic acid 22:6, N-3). Chow and HFD groups were pair fed to equalize caloric intake. Thus HFD-fed mice were given less food than same sex chow-fed mice. The chow and HFDs had closely matched amounts of protein $(0.243 \mathrm{~g} / \mathrm{g}$ chow, 0.237 $\mathrm{g} / \mathrm{g}$ HFD) and carbohydrates (0.402 g/g chow, 0.414 $\mathrm{g} / \mathrm{g}$ HFD), but quite different amounts of fat $(0.047 \mathrm{~g} / \mathrm{g}$ chow, $0.236 \mathrm{~g} / \mathrm{g}$ HFD). Female's metabolism, including energy balance, lipid metabolism, and glucose homeostasis, is influenced by estrogens [25-28], especially during proestus-estrus when endogenous estrogen is high and has greatest physiological effects [29]. Phases of ovarian cycles were determined by predominant cell types of vaginal cytology samples. Females (36 out of 40) that displayed normal cyclicity were fed a diet for four days, beginning in estrus and terminating during proestrus-estrus. All procedures were approved by the Institutional Animal Care and Use Committee at Miami University Ohio.

\section{Sample collection}

On the last day mice were food deprived for 2 hours (0700-0900), so that all mice had similar meal status. 
Blood glucose of mice was measured using blood samples obtained from tip of the tail vein with a glucose meter (Infinity ${ }^{\circledR}$, US Diagnostics, New York, NY). Mice were then injected intraperitoneally with saline or insulin (1 mU/g; Sigma, St. Louis, MO), and sacrificed 15 min after injection. Plasma of blood collected from the hepatic portal vein (HPV) was used to measure leptin (ELISA, CrystalChem, Downers Grove, IL) and lipids (Wako Diagnostics, Richmond, VA), including high and low density lipoprotein-cholesterol (HDL-C, LDL-C), FFA, and triglyceride (TG). Liver, soleus muscle with great abundance of highly oxidative fibers, and gonadal epididymal (male) or parametrial (female) WAT were collected and frozen at $-80^{\circ} \mathrm{C}$ until extractions for liver TG, protein, and total RNA. Gonadal WAT has greater expression level of inflammation-related genes, such as macrophage infiltration marker monocyte chemoattractant protein-1 (Mcp-1) and a macrophage-specific marker $C d 68$ [11], and contains less connective tissue and fewer vessels than subcutaneous WAT and visceral WAT, assuring accuracy in analysis of protein activity and gene expression. Plasma measurements and gene expression levels were not significantly different between saline- and insulin-injected groups within the same diet of each sex $(P>0.05)$, analyzed by unpaired two-tailed t tests, and therefore data were combined.

\section{Liver TG measurement}

Liver tissue $(\sim 50 \mathrm{mg})$ was lysed in chloroform and methanol mixture, re-dissolved in Infinity ${ }^{\circledR}$ TG stable reagent (Thermo Scientific), and measured with TG multi calibrator (Wako Diagnostics) at absorbance of $600 \mathrm{~nm}$ [30]. TG content was calculated to $\mu \mathrm{g}$ TG per mg liver.

\section{Gene expression using quantitative PCR}

Total RNA was extracted and reverse transcribed into cDNA using $1 \mu \mathrm{g}$ RNA. Genes implicated in de novo lipogenesis (fatty acid synthase, Fas; acetyl coenzyme carboxylase, $A c c$; sterol-regulatory element binding protein-1c, Srebp-1c), mitochondrial fatty acid $\beta$-oxidation (PPAR gamma coactivator, $\operatorname{Pgcl} \alpha$ ), and low-grade inflammation $(M c p-1, C d 68)$ were analyzed (Table 1). Glyceraldehyde-3-phosphate dehydrogenase (Gapdh) mRNA levels were similar among dietary groups and Gapdh was used as a reference gene. Quantitative PCR was run in triplicates using iQ SYBR Green Supermix (Bio-Rad, Hercules, CA) and an iCycler (Bio-Rad) with 40 cycles of amplification $\left(95{ }^{\circ} \mathrm{C}\right.$ for $\left.10 \mathrm{~s}\right)$ and annealing $\left(58^{\circ} \mathrm{C}\right.$ for $\left.30 \mathrm{~s}\right)$. The amplified products were confirmed via gel electrophoresis and melt curve analysis. Results were calculated by a $2^{-\Delta \Delta \mathrm{Ct}}$ method, and presented using chow groups as $100 \%$.

\section{Tissue insulin sensitivity using western blot}

Protein was extracted by homogenizing using lysis buffer with sodium orthovanadate, phenylmethylsulfonyl fluoride, protease inhibitor (Santa Cruz

Table 1 Quantitative PCR primer sequences.

\begin{tabular}{|c|c|c|}
\hline Genes & GenBank accession number & Forward and reverse primer sequences \\
\hline Gapdh & NC_000072 & $\begin{array}{l}\text { F: 5'- GCGACTTCAACAGCAACTC-3' } \\
\text { R: 5'- GCCTCTCTTGCTCAGTGTCC-3' }\end{array}$ \\
\hline Fas & NM_007988 & $\begin{array}{l}\text { F: 5'-TCACCACTGTGGGCTCTGCAGAGAAGCGAG-3' } \\
\text { R: 5'-TGTCATTGGCCTCAAAAAGGGCGTCCA-3' }\end{array}$ \\
\hline$A c c$ & NM_133360 & $\begin{array}{l}\text { F: 5'-CCCAGCAGAATAAAGCTACTTTGG-3' } \\
\text { R: 5'-TCCTTTTGTGCAACTAGGAACGT-3' }\end{array}$ \\
\hline Srebp-1c & NM_011480 & $\begin{array}{l}\text { F: 5'-GGCACTAAGTGCCCTCAACCT-3' } \\
\text { R: 5'-GCCACATAGATCTCTGCCAGTGT-3' }\end{array}$ \\
\hline $\operatorname{Pgcl\alpha }$ & NR_027710 & $\begin{array}{l}\text { F: 5'-ATGTGTCGCCTTCTTGCTCT-3' } \\
\text { R: 5'-ATCTACTGCCTGGGGACCTT-3' }\end{array}$ \\
\hline Cd68 & NM_009853 & $\begin{array}{l}\text { F: 5'-TTCTGCTGTGGAAATGCAAG -3', } \\
\text { R: 5'-AGAGGGGCTGGTAGGTTGAT-3' }\end{array}$ \\
\hline$M c p-1$ & NM_011333 & $\begin{array}{l}\text { F: 5'-CCCAATGAGTAGGCTGGAGA-3' } \\
\text { R: 5'-TCTGGACCCATTCCTTCTTG-3' }\end{array}$ \\
\hline
\end{tabular}

Glyceraldehyde-3-phosphate dehydrogenase (Gapdh), fatty acid synthase (Fas), acetyl co-enzyme carboxylase $(A c c)$, sterol-regulatory binding protein-1c $(S r e b p-1 c)$, peroxisome proliferatoractivated receptor gamma coactivator $1 \alpha(P g c l \alpha)$, macrophage-specific marker $(C d 68)$, and monocyte chemoattractant protein-1 (Mcp-1). 
Biotechnology, Santa Cruz, CA) and phosphatase inhibitor cocktail (Sigma). Protein lysates were resolved in $4-15 \%$ tris-glycine gels and transferred to nitrocellulose membrane (Bio-Rad). Activity of kinase Akt indicates stimulated insulin signaling. Phosphorylated and total Akt (Ser ${ }^{473}$ pAkt, tAkt; 1:1000; Cell Signaling, Danvers, MA) were detected by immunoblotting via chemiluminescence (Amersham ${ }^{\mathrm{TM}}$ ECL $^{\mathrm{TM}}$ Prime, GE Healthcare) and visualized using autoradiography film. Density was quantified using ImageQuant software (Amersham Biosciences). pAkt measurements were normalized to tAkt (pAkt/tAkt). Activation of insulin signaling was indicated by $\mathrm{pAkt} / \mathrm{tAkt} \%$ difference between insulin- and saline-injected mice.

\section{Statistical analysis}

Data were presented as mean \pm SEM. Prism $5(\mathrm{La}$ Jolla, CA) was used to perform two-way repeatedmeasures ANOVA comparing day and diet followed by Bonferroni posttest to analyze daily body mass, and two-way ANOVA comparing sex and diet followed by Bonferroni posttest to analyze body and WAT mass, leptin, glucose, lipids, gene expression levels, and insulin signaling. A test with $P<0.05$ was considered statistically significant.

\section{Results}

Body mass, WAT mass, circulating leptin and glucose Male mice consumed greater amount of chow than females during acclimation (male $4.32 \pm 0.12 \mathrm{~g} /$ day or $12.98 \pm 0.35 \mathrm{kcal} /$ day $v s$. female $3.97 \pm 0.11 \mathrm{~g} /$ day or $11.91 \pm 0.34 \mathrm{kcal} /$ day; $\left.\mathrm{t}_{66}=2.16 ; P=0.03\right)$. During the four-day experiment period, each male and female mouse was fed daily $12.98 \mathrm{kcal}(4.32 \mathrm{~g}$ chow or 2.75 $\mathrm{g}$ one of HFDs) and $11.91 \mathrm{kcal}$ (3.97 $\mathrm{g}$ chow or $2.52 \mathrm{~g}$ one of HFDs), respectively. Effort was made to accurately weigh food with less than $\pm 0.10 \mathrm{~g}$ of variation. The majority of food was consumed every day, with a little food occasionally remaining when next meal was provided. All four groups of each sex consumed equal amounts of calories during 4-day feeding. As a result, body mass was similar among dietary groups of males (Fig. 1A) and females (Fig. 1B), indicated by twoway repeated-measures ANOVA. Day affected body mass of males $\left[\mathrm{F}_{4,112}=78.09, P<0.0001\right]$ and females $\left[\mathrm{F}_{4,128}=13.19, \quad P<0.0001\right]$, but diet did not affect body mass of males $\left[\mathrm{F}_{3,28}=2.58, P=0.07\right]$ or females $\left[\mathrm{F}_{3,32}=1.25, P=0.31\right]$. At the end of this experiment, male mice weighed more than the same diet females (Fig. 1C). Two-way ANOVA revealed that body mass was affected by sex $\left[\mathrm{F}_{1,60}=249.33, P<0.0001\right]$, but not by diet $\left[\mathrm{F}_{3,60}=1.55, P=0.21\right]$. There was no interaction between diet and sex $\left[\mathrm{F}_{3,60}=1.56, P=0.21\right]$.

Although all male groups had similar body mass, SFA and MUFA males had greater gonadal WAT mass than chow and PUFA males. HFD males had greater WAT mass compared to female counterparts (Fig. 1D). Both diet $\left[\mathrm{F}_{3,60}=7.97, P=0.0001\right]$ and sex $\left[\mathrm{F}_{1,60}=48.93\right.$, $P<0.0001]$ affected gonadal WAT mass, but there was no interaction between diet and sex $\left[\mathrm{F}_{3,60}=2.31, P=0.09\right]$. The significant difference in body mass between males and females would impact sex difference in WAT mass, thus WAT mass data were adjusted by dividing gonadal WAT mass by body mass. After adjusted for body mass gonadal WAT mass/body mass was similar between male and female chow groups, but elevated WAT mass persisted in SFA and MUFA males (Fig. 1E). Furthermore, WAT mass/body mass was greater in MUFA males than MUFA females (Fig. 1E). ANOVA revealed similar statistical results for WAT mass and WAT mass/body mass, i.e., both diet $\left[\mathrm{F}_{3,60}=6.92\right.$, $P=0.0004]$ and sex $\left[\mathrm{F}_{1,60}=18.89, P<0.0001\right]$ affected WAT mass/body mass, with no interaction between diet and $\operatorname{sex}\left[\mathrm{F}_{3,60}=1.58, P=0.20\right]$.

Leptin level indicates total adiposity. The difference in WAT mass was reflected by higher plasma leptin concentrations in SFA and MUFA males than their female counterparts as well as chow and PUFA male counterparts (Fig. 1F). Both diet $\left[\mathrm{F}_{3,60}=16.76, P<0.0001\right]$ and sex $\left[\mathrm{F}_{1,60}=41.32, P<0.0001\right]$ affected leptin level, and there was an interaction between diet and sex $\left[\mathrm{F}_{3,60}=9.87, P<0.0001\right]$. MUFA and PUFA females had higher glucose levels than chow females (Fig. $1 \mathrm{G})$, and PUFA females had higher blood glucose than SFA females (Fig. 1G). Glucose levels were higher in chow and SFA males than the same diet females (Fig. $1 \mathrm{G})$. ANOVA revealed an interaction between sex and diet $\left[\mathrm{F}_{3,60}=4.36, P=0.008\right]$ on blood glucose, which was affected by both $\operatorname{diet}\left[\mathrm{F}_{3,60}=2.69, P=0.05\right]$ and sex $\left[\mathrm{F}_{1,60}=20.45, P<0.0001\right]$.

\section{Plasma lipid and liver lipid}

LDL-C levels were higher in SFA males as well as SFA and MUFA females than their same sex chow and PUFA counterparts, and were also higher in HFD females than the same diet male groups (Fig. 2A). ANOVA indicated that both $\operatorname{diet}\left[\mathrm{F}_{3,60}=14.09\right.$, 
A

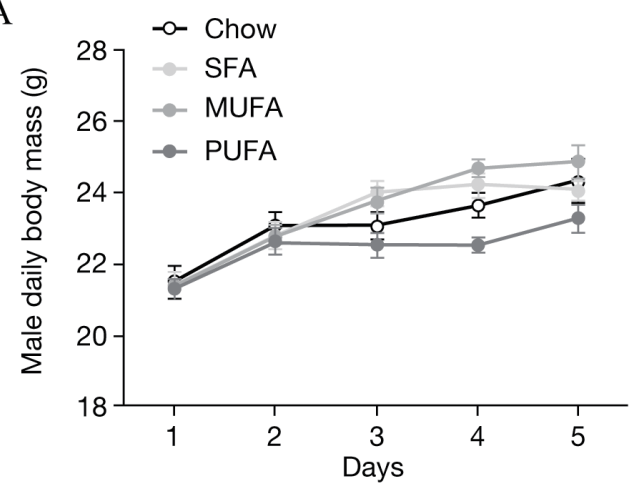

$\mathrm{C}$
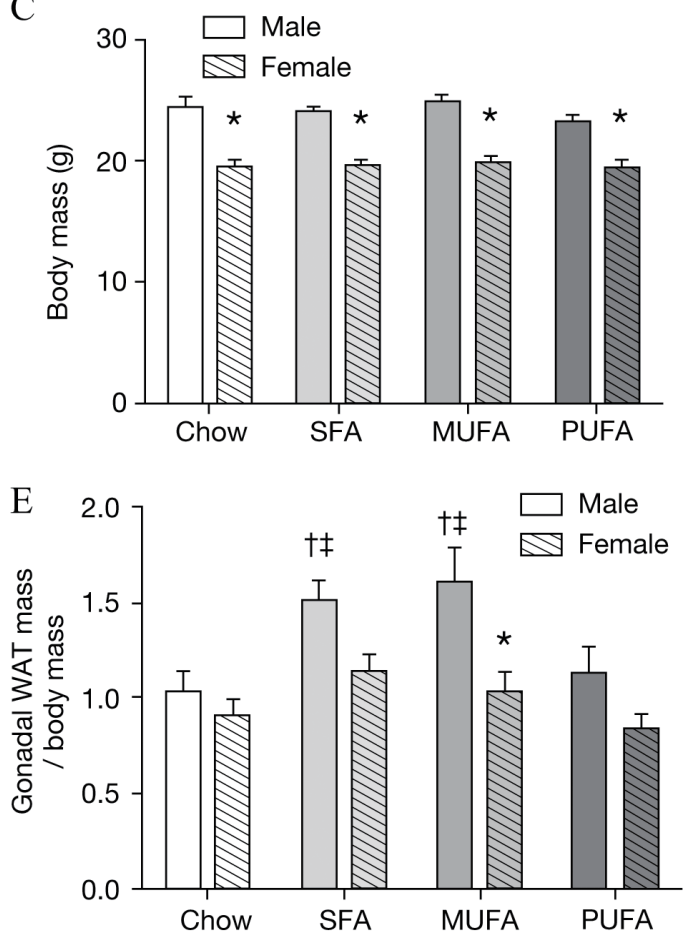

G

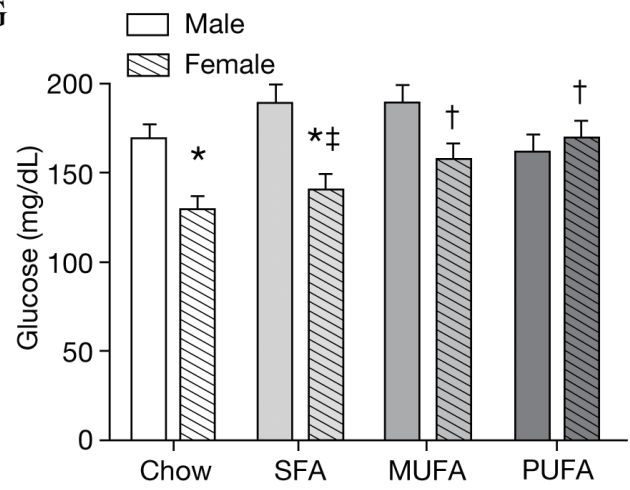

$\mathrm{B}$

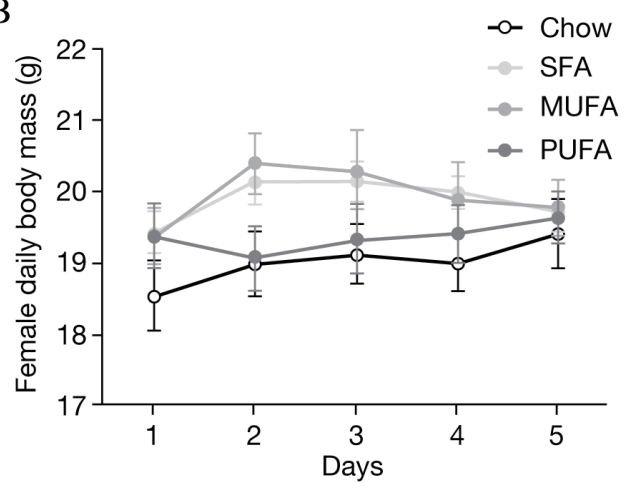

$\mathrm{D}$

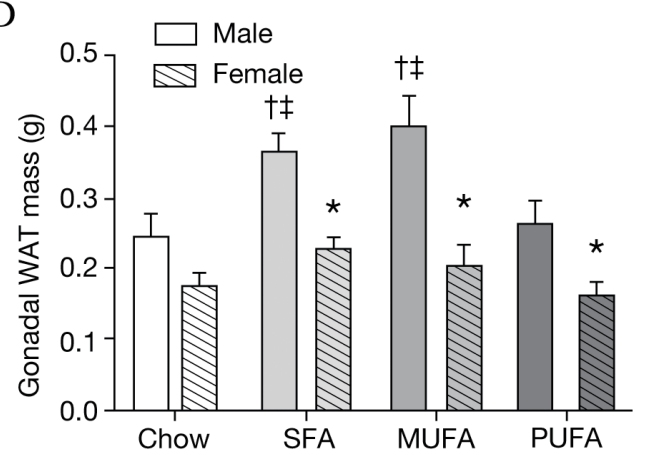

F

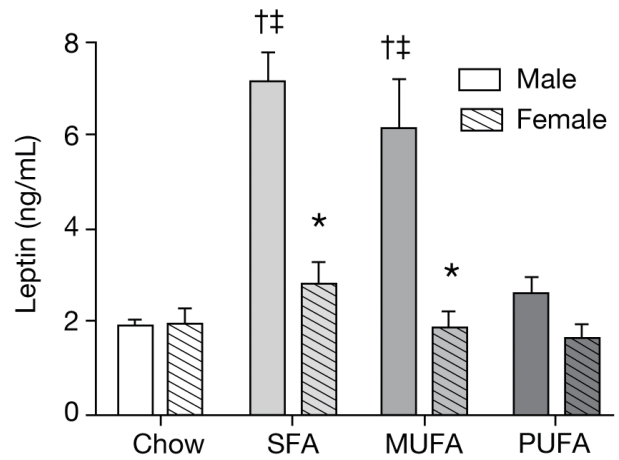

Fig. 1 Body mass, gonadal white adipose tissue (WAT) mass, leptin levels, and glucose levels of male and female mice

Daily body mass of males (A) and females (B) were analyzed by a repeated measures two-way ANOVA (day x diet) followed by Bonferroni posttest. Terminal body mass (C), gonadal WAT mass (D), gonadal WAT mass/body mass (E), plasma leptin level (F), and blood glucose (G) were analyzed by a two-way ANOVA (sex x diet) followed by Bonferroni posttest. $*$, Significantly different between sexes; $\uparrow$, Significantly different comparing to the same sex chow group; $\$$, Significantly different comparing to the same sex PUFA group 
$P<0.0001]$ and sex $\left[\mathrm{F}_{1,60}=49.55, P<0.0001\right]$ affected LDL-C levels, but there was no interaction between diet and sex $\left[\mathrm{F}_{3,60}=1.85, P=0.15\right]$. HDL-C levels were higher in SFA females than SFA males, and were higher in SFA and PUFA females than chow females (Fig. 2B). Sex $\left[\mathrm{F}_{1,60}=4.21, P=0.0446\right]$ but not diet $\left[\mathrm{F}_{3,60}=2.46, P=0.07\right]$ affected HDL-C level, and there was no interaction between diet and $\operatorname{sex}\left[\mathrm{F}_{3,60}=1.72\right.$, $P=0.17]$. A more meaningful indicator is HDL/LDL ratio that denotes risk for incidence of CVD [31]. SFA males had lower HDL/LDL than chow and PUFA males, and MUFA females had lower HDL/LDL than PUFA females and MUFA males (Fig. 2C). HDL/LDL was affected by both diet $\left[\mathrm{F}_{3,60}=3.98, P=0.01\right]$ and sex $\left[\mathrm{F}_{1,60}=10.18, P=0.002\right]$, but there was no interaction between diet and sex $\left[\mathrm{F}_{3,60}=2.08, P=0.11\right]$.

Plasma FFA concentrations were higher in SFA and MUFA males than chow and PUFA males. Additionally,
FFA levels were higher in males than the same diet females (Fig. 2D). ANOVA indicated that FFA was affected by sex $\left[\mathrm{F}_{1,60}=121.24, P<0.0001\right]$ but not diet $\left[\mathrm{F}_{3,60}=2.24, P=0.09\right]$, and revealed a significant interaction between diet and sex $\left[\mathrm{F}_{3,60}=2.86, P=0.04\right]$. Plasma TG concentrations were similar between same diet male and female groups. PUFA males and females had lower plasma TG levels than the same sex chow mice (Fig. 2E). Diet $\left[\mathrm{F}_{3,60}=7.99, P=0.0001\right]$, but not sex $\left[\mathrm{F}_{1,60}=1.56, P=0.22\right]$, affected plasma TG levels, with no interaction between diet and $\operatorname{sex}\left[\mathrm{F}_{3,60}=0.06\right.$, $P=0.98]$. Among the male groups, MUFA males had highest liver TG content than other male groups, and SFA males had higher liver TG than chow and PUFA males, indicating hepatic lipid accumulation in SFA and MUFA males. When compared between sexes within same diets, liver TG was higher in MUFA males and PUFA females (Fig. 2F). ANOVA revealed that liver
A

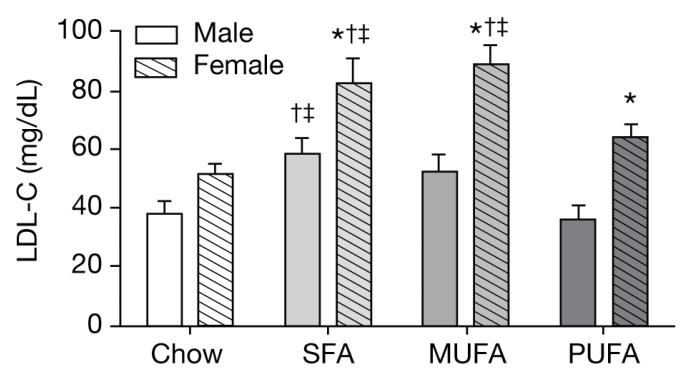

$\mathrm{C}$

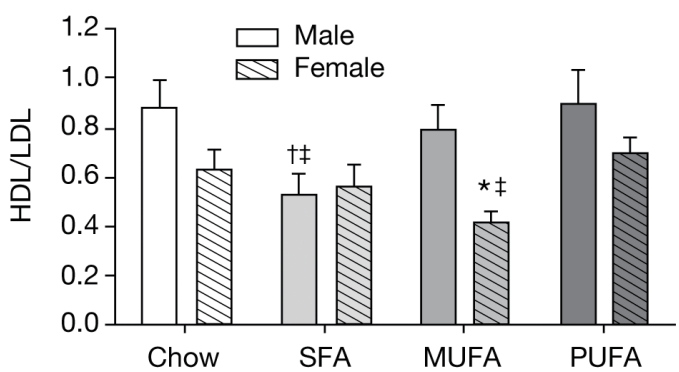

$\mathrm{E}$

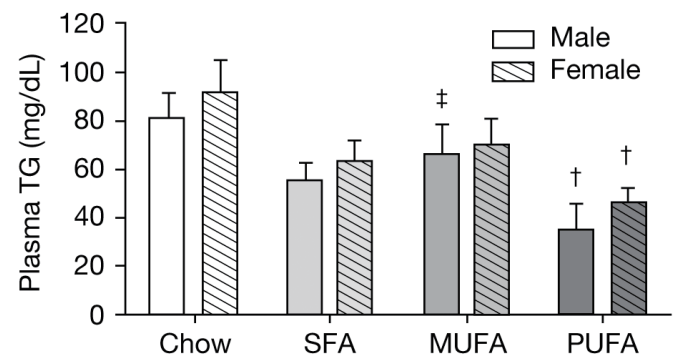

B

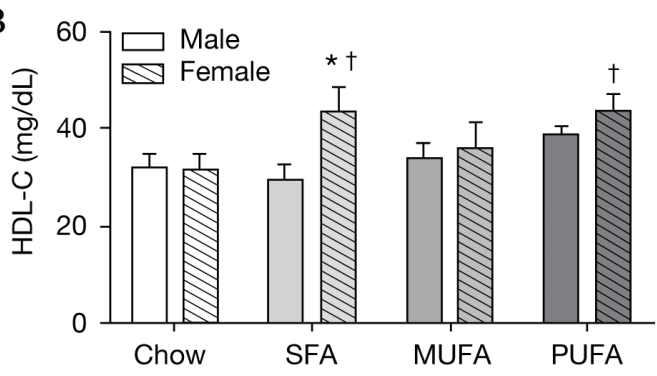

$\mathrm{D}$

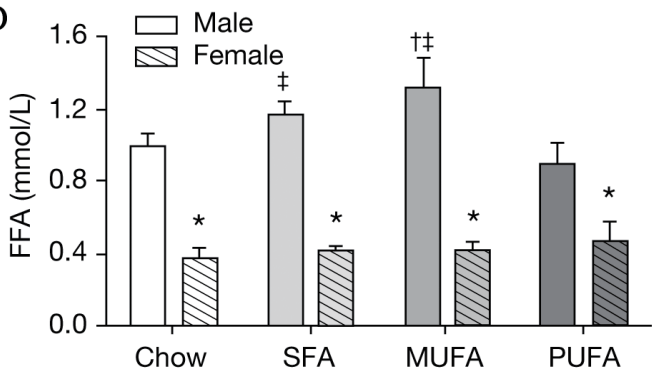

$\mathrm{F}$

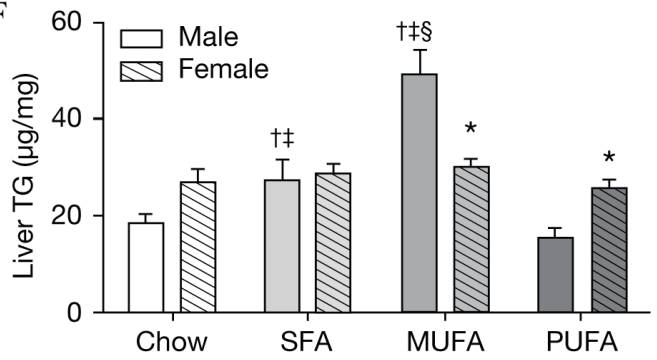

Fig. 2 Lipid analysis of plasma samples from the hepatic portal vein and liver lipid content of male and female mice

Plasma lipid levels, including LDL-cholesterol (LDL-C; A), HDL-cholesterol (HDL-C; B), HDL/LDL ratio (C), free fatty acid (FFA; D), triglyceride (TG; E), and liver TG content (F) were analyzed by a two-way ANOVA (sex x diet) followed by Bonferroni posttest. *, Significantly different between sexes; $\uparrow$, Significantly different comparing to the same sex chow group; $\$$, Significantly different comparing to the same sex PUFA group; $\S$, Significantly different comparing to the same sex SFA group 
Table 2 Liver gene expression levels measured in male and female mice

\begin{tabular}{|c|c|c|c|c|c|c|}
\hline & & Chow & SFA & MUFA & PUFA & ANOVA \\
\hline \multirow[t]{2}{*}{ Fas } & Male & $100 \pm 33.07$ & $51.69 \pm 7.31$ & $54.63 \pm 18.84$ & $\begin{array}{l}25.37 \pm 10.20 \\
\quad \dagger P<0.01\end{array}$ & $\begin{array}{c}\text { D: } \mathrm{F}_{3,60}=5.03, P=0.004 \\
\mathrm{~S}: \mathrm{F}_{1,60}=0.64, P=0.43\end{array}$ \\
\hline & Female & $100 \pm 23.96$ & $85.32 \pm 17.59$ & $61.87 \pm 19.04$ & $\begin{array}{l}27.61 \pm 8.93 \\
\quad \dagger P<0.05\end{array}$ & DxS: $\mathrm{F}_{3,60}=0.33, P=0.80$ \\
\hline \multirow[t]{2}{*}{$A c c$} & Male & $100 \pm 27.25$ & $67.44 \pm 7.55$ & $95.80 \pm 29.95$ & $52.12 \pm 10.27$ & $\begin{array}{l}\text { D: } F_{3,60}=3.68, P=0.02 \\
\mathrm{~S}: \mathrm{F}_{160}=3.74, P=0.06\end{array}$ \\
\hline & Female & $100 \pm 19.32$ & $109.31 \pm 10.03$ & $\begin{array}{c}141.95 \pm 21.81 \\
\ddagger P<0.01\end{array}$ & $65.52 \pm 8.79$ & DxS: $F_{3,60}=0.72, P=0.54$ \\
\hline \multirow[t]{2}{*}{ Srebp-1c } & Male & $100 \pm 43.37$ & $102.42 \pm 26.73$ & $98.94 \pm 37.41$ & $77.04 \pm 25.08$ & $\begin{array}{c}\text { D: } \mathrm{F}_{3,60}=2.21, P=0.10 \\
\underline{\mathrm{S}}: \mathrm{F}_{1,60}=9.30, P=0.003\end{array}$ \\
\hline & Female & $100 \pm 22.17$ & $185.10 \pm 36.85$ & $\begin{array}{c}282.22 \pm 68.84 \\
* P<0.001 ; \dagger P<0.01 \\
\quad+P<0.05\end{array}$ & $144.75 \pm 19.39$ & DxS: $F_{3,60}=1.91, P=0.14$ \\
\hline \multirow[t]{2}{*}{ Pgcla } & Male & $100 \pm 25.27$ & $210.00 \pm 55.50$ & $\begin{array}{c}368.09 \pm 114.15 \\
\dagger P<0.001 ; \S P<0.05 ; \\
\quad+P<0.001\end{array}$ & $102.54 \pm 45.81$ & $\begin{array}{l}\underline{\mathrm{D}}: \mathrm{F}_{3,60}=3.46, P=0.022 \\
\underline{\mathrm{S}}: \mathrm{F}_{1,60}=10.01, P=0.002 \\
\underline{\mathrm{DxS}}: \mathrm{F}_{3,60}=3.77, P=0.02\end{array}$ \\
\hline & Female & $100 \pm 18.03$ & $71.92 \pm 13.68$ & $\begin{array}{l}93.03 \pm 19.32 \\
\quad * P<0.001\end{array}$ & $93.66 \pm 12.38$ & \\
\hline
\end{tabular}

$\overline{\text { Gene expression levels of chow groups were set at 100\%. Liver gene expression levels of fatty acid synthase (Fas), }}$ acetyl co-enzyme carboxylase $(A c c)$, transcription factor for lipogenic enzymes sterol-regulatory binding protein-1c $($ Srebp-1c), and peroxisome proliferator-activated receptor gamma coactivator $1 \alpha(P g c l \alpha)$ were analyzed by twoway ANOVA (sex x diet) followed by Bonferroni posttest. *, Significantly different between sexes; †, Significantly different comparing to the same sex chow group; $\$$, Significantly different comparing to the same sex PUFA group; $\S$, Significantly different comparing to the same sex SFA group

TG was affected by diet $\left[\mathrm{F}_{3,60}=21.78, P<0.0001\right]$ but not sex $\left[\mathrm{F}_{1,60}=0.03, P=0.86\right]$, and there was an interaction between diet and sex $\left[\mathrm{F}_{3,60}=13.41, P<0.0001\right]$.

\section{Gene expression involved in hepatic lipogenesis and lipid oxidation}

Hepatic lipid accumulation could be due to increased de novo lipogenesis (Fas, Acc, Srebp-1c) and/or reduced lipid $\beta$-oxidation $(P g c l \alpha)$. Although all HFD groups showed a trend to lower Fas mRNA levels compared with chow groups, only male and female PUFA groups reached significance. Acc and $S r e b p-1 c$ mRNA levels were comparable among male groups. In contrast MUFA females had greater Acc expression than PUFA females and greater Srebp-1c mRNA levels than chow and PUFA females. MUFA females also had greater Srebp-1c expression than their male counterparts. MUFA males had greatest Pgcl $\alpha$ expression than other male groups and MUFA females. Expression of Srebp-1c was affected by sex alone, while Fas and Acc mRNA levels were affected by diet alone. Hepatic expression of Pgcl $\alpha$ was affected by both sex and diet, with an interaction between diet and sex (Table 2).

\section{Insulin signaling}

Insulin sensitivity was indicated by pAkt/tAkt $\%$.
WAT pAkt $/ \mathrm{tAkt} \%$ was greater in insulin- than salineinjected chow males, whereas it was not different between saline- and insulin-injected HFD males (Table 3 WAT Male), indicating that WAT of chow males, but not HFD males, was sensitive to insulin stimulation. WAT pAkt $/ \mathrm{tAkt} \%$ was greater in insulin-injected females than same diet saline-injected females (Table 3 WAT Female). Activation of WAT insulin signaling was greater in SFA females than PUFA and MUFA females as well as SFA males, while it was less in PUFA females than chow females (Fig. 3). ANOVA revealed that insulin sensitivity in WAT was affected by sex $\left[\mathrm{F}_{1,28}=17.62, P=0.0002\right]$, but not diet $\left[\mathrm{F}_{3,28}=2.70\right.$, $P=0.06]$, with an interaction between sex and diet $\left[\mathrm{F}_{3,28}=3.34, P=0.03\right]$.

Muscle of chow males, but not HFD males, displayed greater $\mathrm{pAkt} / \mathrm{tAkt} \%$ after insulin injection compared with saline injection (Table 3 Muscle Male). Insulin-injected chow, MUFA, and PUFA females, but not SFA females, had greater muscle $\mathrm{pAkt} / \mathrm{tAkt} \% \mathrm{com}-$ pared with their saline-injected counterparts (Table 3 Muscle Female), indicating that except SFA females, all other female groups were insulin sensitive in muscle tissue. ANOVA indicated that sex affected insulin activity in muscle with females having greater muscle $\mathrm{pAkt} / \mathrm{tAkt} \%$ than males $\left[\mathrm{F}_{1,28}=4.43, P=0.04\right]$, although 
Table 3 Activation of insulin signaling in gonadal WAT, muscle and liver of male and female mice

\begin{tabular}{|c|c|c|c|c|c|c|}
\hline \multicolumn{2}{|c|}{ pAkt/tAkt (\%) } & & Chow & SFA & MUFA & PUFA \\
\hline \multirow{5}{*}{ WAT } & Male & $\mathrm{S}$ & $100 \pm 7.27$ & $100 \pm 20.05$ & $100 \pm 7.28$ & $100 \pm 40.27$ \\
\hline & & I & $\begin{array}{c}169.58 \pm 25.88 \\
\text { व } P<0.05\end{array}$ & $127.80 \pm 35.36$ & $115.68 \pm 46.13$ & $179.80 \pm 29.81$ \\
\hline & Female & $\mathrm{S}$ & $100 \pm 70.86$ & $100 \pm 34.73$ & $100 \pm 3.06$ & $100 \pm 13.28$ \\
\hline & & I & $338.54 \pm 20.13$ & $413.25 \pm 92.30$ & $205.20 \pm 23.09$ & $184.47 \pm 29.41$ \\
\hline & & & I $P<0.0001$ & | $P<0.05$ & | $P<0.01$ & | $P<0.05$ \\
\hline \multirow{4}{*}{ Muscle } & Male & $\mathrm{S}$ & $100 \pm 14.47$ & $100 \pm 58.79$ & $100 \pm 28.22$ & $100 \pm 28.63$ \\
\hline & & I & $255.88 \pm 5.23$ & $139.10 \pm 33.85$ & $127.86 \pm 20.24$ & $140.31 \pm 37.99$ \\
\hline & Female & $\mathrm{S}$ & $100 \pm 40.68$ & $100 \pm 45.47$ & $100 \pm 38.21$ & $100 \pm 21.10$ \\
\hline & & I & $\begin{array}{c}310.11 \pm 63.52 \\
\quad \mid P<0.05\end{array}$ & $215.73 \pm 74.47$ & $\begin{array}{c}202.06 \pm 32.50 \\
\quad \text { I } P<0.05\end{array}$ & $\begin{array}{c}212.31 \pm 31.93 \\
\quad \mathbb{P}<0.05\end{array}$ \\
\hline \multirow{5}{*}{ Liver } & Male & $\mathrm{S}$ & $100 \pm 5.96$ & $100 \pm 6.68$ & $100 \pm 6.18$ & $100 \pm 4.93$ \\
\hline & & I & $\begin{array}{c}231.60 \pm 2.96 \\
\text { व } P<0.0001\end{array}$ & $154.79 \pm 23.95$ & $123.74 \pm 18.05$ & $138.49 \pm 24.75$ \\
\hline & Female & $\mathrm{S}$ & $100 \pm 20.30$ & $100 \pm 8.76$ & $100 \pm 7.22$ & $100 \pm 21.87$ \\
\hline & & I & $197.16 \pm 30.33$ & $158.25 \pm 19.33$ & $221.10 \pm 26.38$ & $226.94 \pm 39.76$ \\
\hline & & & | $P<0.05$ & \ $P<0.05$ & | $P<0.01$ & | $P<0.05$ \\
\hline
\end{tabular}

pAkt/tAkt $\%$ of saline-injected groups (S) was set at $100 \%$, and pAkt/tAkt $\%$ of insulin-injected groups (I) was calculated relative to saline-injected groups within the same sex and diet. pAkt/ $\mathrm{tAkt} \%$ of saline- and insulin-injected animals was listed at upper and lower rows respectively within each cell. An unpaired two-tailed $t$ test was performed. I, Significantly different comparing to saline-treated group with the same sex and diet

A
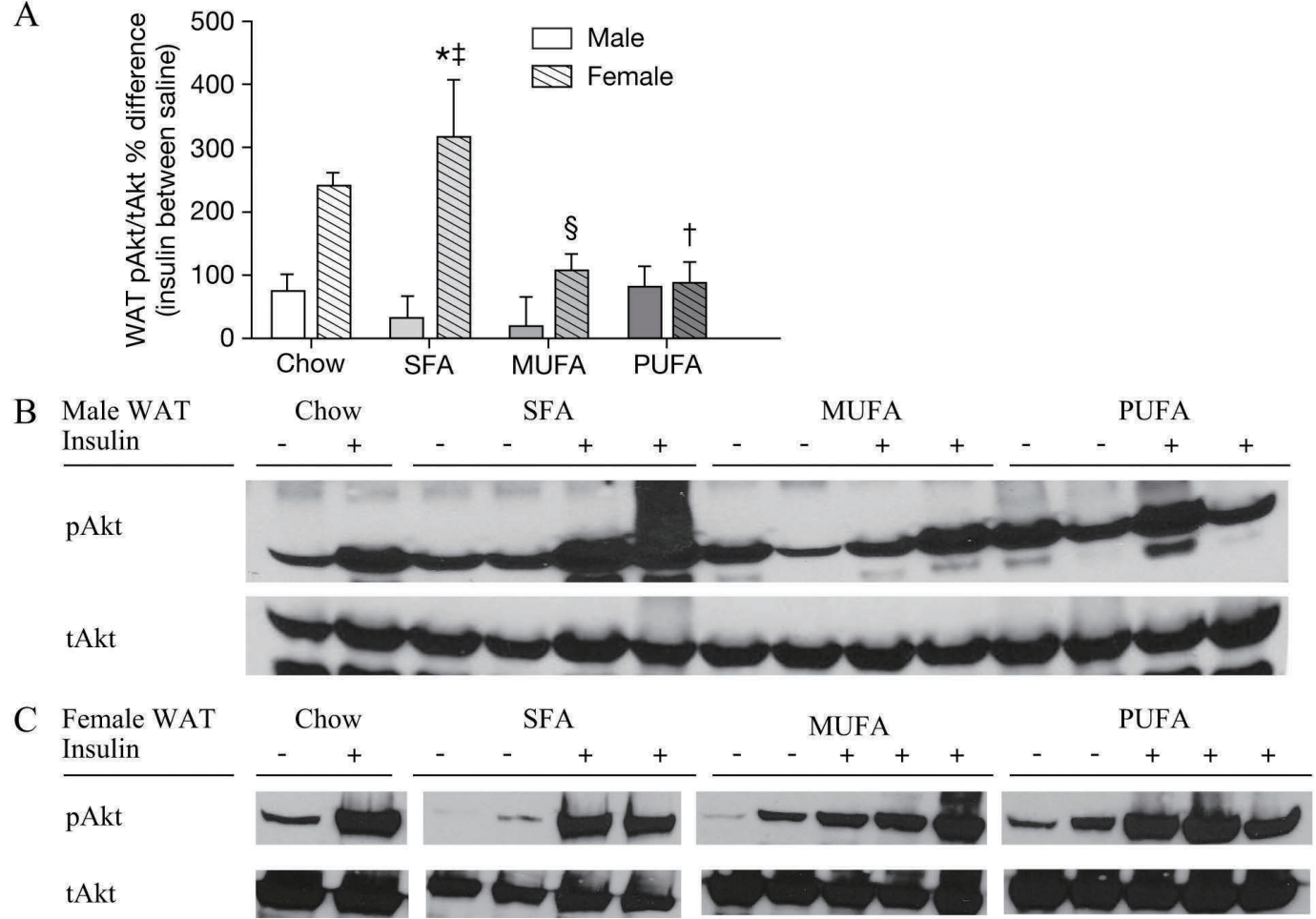

Fig. 3 Analysis of Akt activation in adipose tissue of male and female mice.

A: Percentage differences in pAkt/tAkt ratio at white adipose tissue (WAT) of insulin- vs. saline-treated mice.

$\%$ difference $=(\mathrm{pAkt} / \mathrm{tAkt}$ [insulin] $-\mathrm{pAkt} / \mathrm{tAkt}$ [saline] $) /$ average pAkt/tAkt [saline] x 100\%; pAkt/tAkt [saline]: pAkt/tAkt of each saline-injected animal; pAkt/tAkt [insulin]: pAkt/tAkt of each insulin-injected animal; average pAkt/tAkt [saline]: average of pAkt/tAkt of all saline-injected animals from a group. Two-way ANOVA (sex x diet) followed by Bonferroni posttest was performed. *, Significantly different between sexes; $\uparrow$, Significantly different comparing to the same sex chow group; $\ddagger$, Significantly different comparing to the same sex PUFA group; $\S$, Significantly different comparing to the same sex SFA group. B-C: Western blot analysis of pAkt and tAkt expression in WAT of males (B) and females (C). Representative data from one experiment shown. 


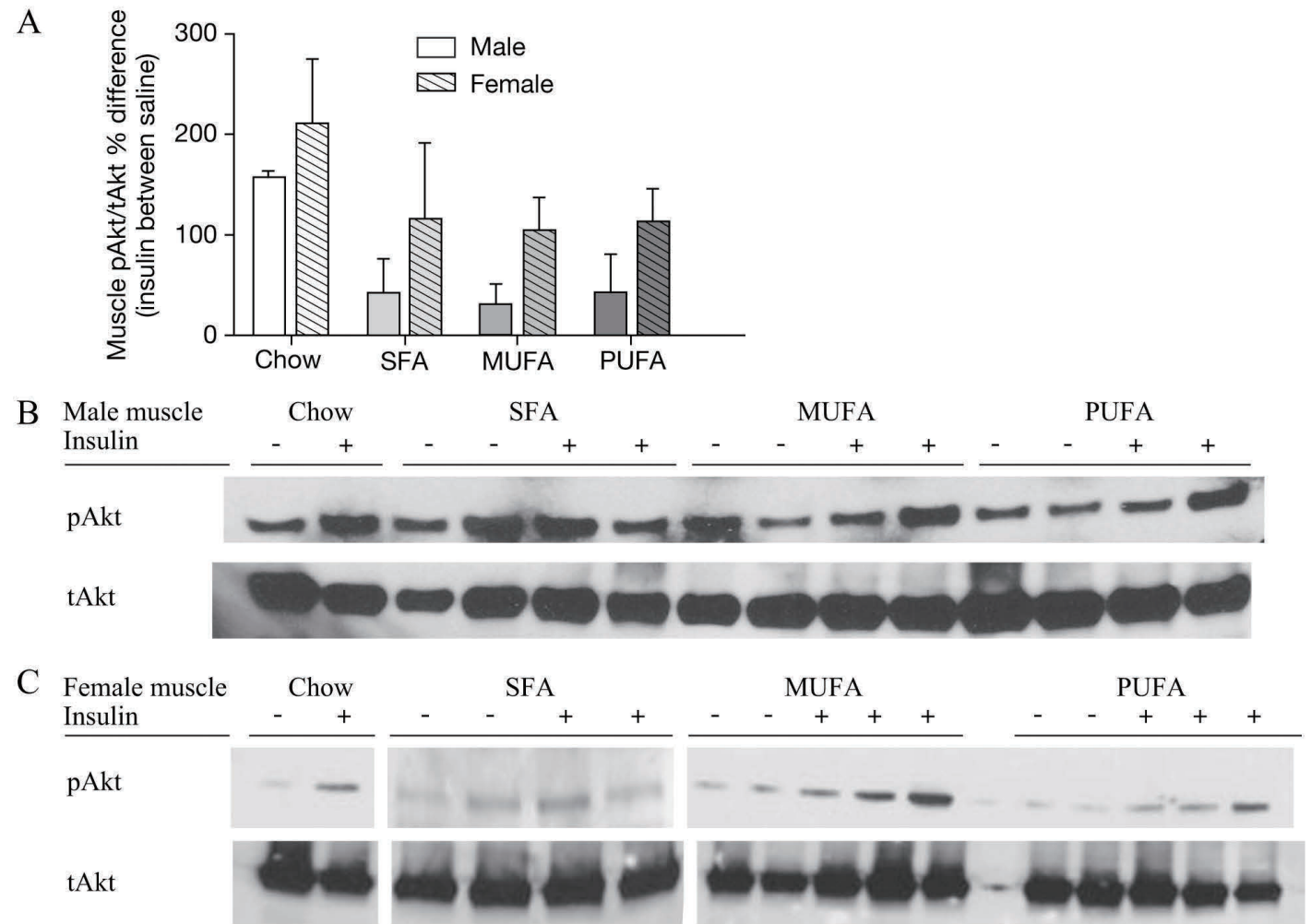

Fig. 4 Analysis of Akt activation in skeletal muscle of male and female mice.

A: Percentage differences in pAkt/tAkt ratio in skeletal muscle of insulin- vs. saline-treated mice. Two-way ANOVA (sex $\mathrm{x}$ diet) followed by Bonferroni posttest was performed. B-C: Western blot analysis of pAkt and tAkt expression in skeletal muscle of males (B) and females (C). Representative data from one experiment shown.

Bonferroni posthoc analysis did not reveal difference within any diet group (Fig. 4). Diet did not affect muscle insulin activity $\left[\mathrm{F}_{3,28}=2.83, P=0.06\right]$, and there was no interaction between diet and sex $\left[\mathrm{F}_{3,28}=0.02, P=0.99\right]$.

Insulin injection significantly elevated liver pAkt/ tAkt $\%$ of chow males. In contrast, liver pAkt $/ \mathrm{tAkt} \%$ was similar between saline- and insulin-injected HFD males, indicating that liver of HFD males were insulin resistant (Table 3 Liver Male). Liver pAkt $/ \mathrm{tAkt} \%$ was greater in insulin-injected females than saline-injected same diet females, indicating normal liver insulin signaling in females (Table 3 Liver Female). MUFA males had lower liver insulin activation than chow males, and SFA females had lower insulin activation than PUFA females. MUFA and PUFA females had greater liver insulin activation compared to their male counterparts (Fig. 5). Similar as WAT, ANOVA revealed that insulin sensitivity in liver was affected by sex $\left[\mathrm{F}_{1,28}=4.16, P=0.05\right]$ but not $\operatorname{diet}\left[\mathrm{F}_{3,28}=1.66, P=0.20\right]$, and there was an interaction between sex and diet $\left[\mathrm{F}_{3,28}=2.89, P=0.05\right]$.

\section{Gene expression levels involved in inflammation}

Defective insulin signaling, indicated by similar $\mathrm{pAkt} / \mathrm{tAkt} \%$ between insulin- and saline-injected mice, might be related to tissue low-grade inflammation. Transcript levels of Cd68 and Mcp-1 in WAT, muscle, and liver were similar among all female groups. In contrast, mRNA levels of Cd68 and Mcp-1 in WAT and muscle were higher in SFA males than chow males, and $C d 68$ and $M c p-1$ expression levels in WAT and $C d 68$ expression in muscle were higher in MUFA males than chow males. SFA and MUFA males had greater WAT expression of $M c p-1$ and $C d 68$, respectively than their female counterparts. Liver expression of $C d 68$ and $M c p-1$ was not altered by diet in either sex. Sex affected mRNA levels of $C d 68$ at all tissues, while diet affected mRNA levels of $C d 68$ and Mcp-1 in WAT and muscle (Table 4). There was a significant interaction between diet and sex on $M c p-1$ expression in WAT (Table 4). 
A

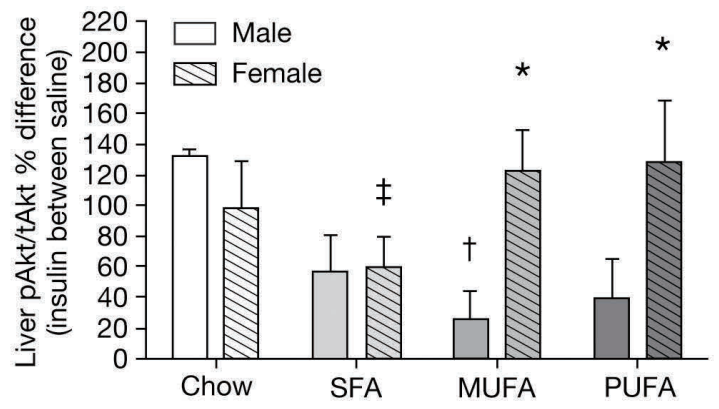

B Male liver Insulin
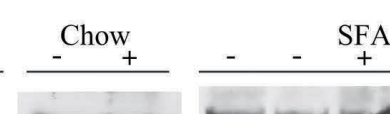

PUFA

pAkt

tAkt

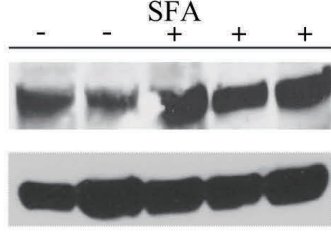

MUFA
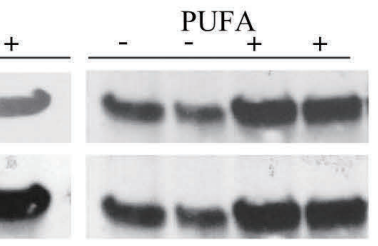

C Female liver Insulin
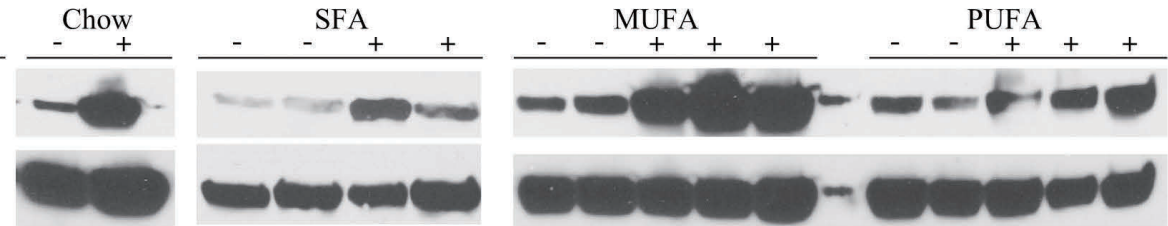

Fig. 5 Analysis of Akt activation in the liver tissue of male and female mice.

A: Percentage differences in pAkt/tAkt ratio in the liver of insulin- vs. saline-treated mice. Two-way ANOVA followed by Bonferroni posttest was performed. *, Significantly different between sexes; $\uparrow$, Significantly different comparing to the same sex chow group; $\ddagger$, Significantly different comparing to the same sex PUFA group. B-C: Western blot analysis of pAkt and tAkt expression in the liver of males (B) and females (C). Representative data from one experiment shown.

Table 4 Inflammatory gene expression levels measured in male and female mice.

\begin{tabular}{|c|c|c|c|c|c|c|}
\hline & & Chow & SFA & MUFA & PUFA & ANOVA \\
\hline \multicolumn{7}{|c|}{ WAT } \\
\hline \multirow[t]{2}{*}{ Cd68 } & Male & $100 \pm 14.01$ & $\begin{array}{l}261.43 \pm 46.54 \\
\quad+P<0.01 \\
\quad+P<0.01\end{array}$ & $\begin{array}{c}227.92 \pm 43.82 \\
\quad * P<0.01 ; \\
\dagger P<0.05 ; \ddagger P<0.01\end{array}$ & $81.40 \pm 9.06$ & \multirow[t]{2}{*}{$\begin{array}{l}\text { D: } \mathrm{F}_{3,60}=5.87, \mathrm{P}=0.001 \\
\text { S: } \mathrm{F}_{1,60}=9.15, P=0.004 \\
\mathrm{DxS}: \mathrm{F}_{3,60}=2.40, P=0.08\end{array}$} \\
\hline & Female & $100 \pm 41.01$ & $147.21 \pm 46.57$ & $70.69 \pm 19.67$ & $60.44 \pm 24.76$ & \\
\hline \multirow[t]{2}{*}{$M c p-1$} & Male & $100 \pm 23.55$ & $\begin{array}{c}282.38 \pm 45.68 \\
* P<0.05 \\
\dagger P<0.001 ; \dagger P<0.001\end{array}$ & $\begin{array}{l}247.88 \pm 34.99 \\
\quad \dagger P<0.01 \\
\quad+P<0.01\end{array}$ & $91.43 \pm 26.54$ & \multirow[t]{2}{*}{$\begin{array}{l}\underline{D}: F_{3,60}=6.75, P=0.0005 \\
\text { S: } F_{1,60}=3.73, P=0.06 \\
\underline{D x S}: F_{3,60}=2.96, P=0.04\end{array}$} \\
\hline & Female & $100 \pm 39.11$ & $159.75 \pm 26.57$ & $147.21 \pm 35.27$ & $135.62 \pm 23.55$ & \\
\hline \multicolumn{7}{|c|}{ Muscle } \\
\hline \multirow[t]{2}{*}{ Cd68 } & Male & $100 \pm 15.82$ & $\begin{array}{c}202.97 \pm 12.95 \\
\quad \mapsto P<0.05\end{array}$ & $\begin{array}{c}200.71 \pm 22.27 \\
\quad \dagger P<0.05\end{array}$ & $157.11 \pm 23.80$ & \multirow{2}{*}{$\begin{array}{l}\underline{\mathrm{D}}: \mathrm{F}_{3,60}=4.20, P=0.009 \\
\mathrm{~S}: \mathrm{F}_{1,60}=4.60, P=0.036 \\
\mathrm{DxS}: \mathrm{F}_{3,60}=0.94, P=0.43\end{array}$} \\
\hline & Female & $100 \pm 23.05$ & $179.07 \pm 44.14$ & $115.93 \pm 28.36$ & $102.86 \pm 25.73$ & \\
\hline \multirow[t]{2}{*}{ Mcp-1 } & Male & $100 \pm 14.47$ & $\begin{array}{c}200.71 \pm 21.27 \\
\quad † P<0.01\end{array}$ & $157.11 \pm 23.80$ & $163.37 \pm 18.56$ & \multirow{2}{*}{$\begin{array}{l}\text { D: } \mathrm{F}_{3,60}=4.67, P=0.005 \\
\mathrm{~S}: \mathrm{F}_{1,60}=1.98, P=0.16 \\
\text { DxS: } \mathrm{F}_{3,60}=0.66, P=0.58\end{array}$} \\
\hline & Female & $100 \pm 19.04$ & $160.17 \pm 32.40$ & $156.66 \pm 25.85$ & $116.02 \pm 13.03$ & \\
\hline \multicolumn{7}{|c|}{ Liver } \\
\hline \multirow[t]{2}{*}{ Cd68 } & Male & $100 \pm 15.82$ & $84.19 \pm 8.37$ & $91.95 \pm 23.45$ & $90.76 \pm 18.62$ & \multirow{2}{*}{$\begin{array}{l}\mathrm{D}: \mathrm{F}_{3,60}=0.10, P=0.96 \\
\text { S: } \mathrm{F}_{1,60}=4.68, P=0.035 \\
\text { DxS: } \mathrm{F}_{3,60}=0.56, P=0.64\end{array}$} \\
\hline & Female & $100 \pm 21.09$ & $131.04 \pm 10.63$ & $128.18 \pm 27.12$ & $124.42 \pm 18.22$ & \\
\hline \multirow[t]{2}{*}{$M c p-1$} & Male & $100 \pm 16.02$ & $106.60 \pm 49.45$ & $96.34 \pm 27.19$ & $120.52 \pm 15.06$ & \multirow{2}{*}{$\begin{array}{l}\text { D: } F_{3,60}=0.61, P=0.61 \\
\text { S: } F_{1,60}=1.49, P=0.23 \\
\text { DxS: } F_{3,60}=0.20, P=0.90\end{array}$} \\
\hline & Female & $100 \pm 13.78$ & $143.51 \pm 18.12$ & $125.93 \pm 18.36$ & $141.01 \pm 27.92$ & \\
\hline
\end{tabular}

Gene expression levels of chow groups were set at 100\%. Gene expression levels of a macrophage marker $(C d 68)$ and an inflammation marker for macrophage infiltration monocyte chemoattractant protein-1 (Mcp-1) measured in gonadal white adipose tissue (WAT), soleus muscle (muscle), and liver were analyzed by two-way ANOVA (sex x diet) followed by Bonferroni posttest. *, Significantly different between sexes; $\dagger$, Significantly different comparing to the same sex chow group; $\ddagger$, Significantly different comparing to the same sex PUFA group 


\section{Discussion}

It was thought that diets high in SFA were risk factors for, whereas diets high in UFA were protective against, developing fatty liver and insulin resistance [15-21]. This is the first study to our knowledge that compared sex-specific early effects of different dietary fats on metabolism. Rapid occurrence of low-grade inflammation and insulin resistance by HFDs were sex-specific and tissue-specific. Male HFD groups displayed insulin resistance, whereas female HFD groups had normal liver lipid content and maintained insulin sensitivity in most tissues without inducing tissue inflammation. Although chow and HFD groups consumed equal amounts of calories, SFA and MUFA males had higher leptin levels and greater lipid accumulation in WAT and liver than PUFA and chow males, suggesting that for males, diets rich in SFA and MUFA were more lipogenic than a diet high in PUFA or a lowfat diet. Therefore, beneficial effects of PUFA in prevention of obesity and fatty liver were corroborated. Furthermore, within a meager span of four days, SFA males and MUFA females displayed unhealthy lipid profiles with elevated LDL-C and lower atherogenic index HDL/LDL, indicating high risk of CVD [31]. Thus, MUFA could be a "healthier" type of fat with lower risk for developing CVD compared with SFA for males, but not for females. These findings suggested that different type of dietary fatty acids accounted for metabolic dysfunction.

Estrogens enhance lipid mobilization from fat storage, elevate lipoprotein lipase activity, increase lipoprotein transport [32], and consequently accelerate LDL-C synthesis $[33,34]$. Estrogens also up-regulate LDL-C receptors to increase LDL-C removal from circulation [35], decrease activity of hepatic lipase and impede HDL-C degradation [36]. Thus, females have faster rates for LDL-C synthesis and removal but slower rates for HDL-C removal than males. One evident sex difference in lipid profile was that female HFD groups had higher LDL-C than the male counterparts. This finding seems surprising since estrogen replacement in postmenopausal women reduces LDL-C [37], however when fed diets with increased fat content females have greater increases in LDL-C $[38,39]$ and HDL-C [38, 40] than males. Current data also demonstrated that not all HFDs increased cholesterol, with LDL-C increased in SFA males and SFA and MUFA females, and HDL-C increased in SFA and PUFA females. Another evi- dent sex difference was that females had lower FFA than males. High plasma FFA level is implicated in the pathogenesis of insulin resistance in humans [41]. Elevated FFA level facilitates hepatic gluconeogenesis as well as impairs insulin-mediated glucose uptake and suppression of glucose production [42]. Insulin sensitivity is inversely related to plasma FFA levels in healthy subjects [43]. Females had lower FFA levels and thus were less susceptible to FFA-induced insulin resistance $[23,24]$.

Dietary fat could be stored in adipose tissue and/ or ectopically in non-adipose tissues, a process determined by a balance between lipid storage (lipogenesis) and utilization (lipolysis/ $\beta$-oxidation). Fatty liver is caused by an imbalance between TG assembly and disposal [44]. The major sources of FFA for liver TG assembly are FFA derived from plasma and FFA synthesized de novo in the liver. Increased expression of hepatic lipogenic genes and decreased expression of genes involved in fat oxidation are reported in mice after feeding a HFD for six [45] or eight weeks [46]. Our data clearly indicated that the source of FFA for liver TG assembly in SFA and MUFA males was elevated FFA delivery via HPV (Fig. 2D), rather than de novo hepatic lipogenesis, indicated by similar or reduced expression levels of genes related to FFA synthesis (Table 2). Disposal routes for hepatic TG are fatty acid oxidation and TG export via very low density lipoprotein (VLDL) which is then converted to LDL-C in the bloodstream. Impaired capacity for $\beta$-oxidation was not the case for MUFA males that displayed increased $P g c l \alpha$ mRNA levels, possibly a compensatory response against further lipid accumulation. TG export via VLDL was not measured in this study; however elevated plasma LDL-C levels in SFA and MUFA males indirectly indicated increased TG export, which limited further lipid accumulation.

Chow groups were insulin sensitive, whereas HFD males had defective tissue insulin signaling. In contrast, except for muscle insulin resistance in SFA females, HFD females were insulin sensitive (Table 3 and Figs. 3-5). ANOVA analysis confirmed the effects of sex on insulin sensitivity, revealing significant sex effects at all tissues and interaction between sex and diet in WAT and liver. Tissues of females were collected at proestus-estrus of the ovarian cycles, a phase when female's metabolism is mostly influenced by endogenous estrogens [29]. Besides their roles in reproduction and sexual development, estrogens regulate insulin sensitivity 
by increasing phosphorylation of insulin receptor substrate and Akt in fat and liver [47, 48] and by activating GLUT-4 and glucose transport in muscle [49, 50], which could account for maintaining insulin sensitivity in female HFD groups. There is a strong relationship between fatty liver and insulin resistance in humans. Increased liver TG leads to reduced glucose uptake [51] and insulin resistance [9]. Indeed, rosiglitazone improves insulin sensitivity by decreasing hepatic lipid content [6]. However, PUFA males with normal liver TG had defective tissue insulin signaling. Blood glucose levels were similar among male groups but were elevated in MUFA and PUFA females compared with chow females, which was not correlated with defective insulin signaling in HFD males or normal insulin signaling in MUFA and PUFA females, for reasons that are not clear.

Low-grade inflammation associated with HFD consumption is a crucial factor for obesity-induced insulin resistance [11]. Gene expression analysis of this study indicated that rapid recruitment of macrophages and elevated macrophage infiltration occurred most evidently in WAT and muscle of SFA and MUFA males, although the liver could still be affected by proinflammatory cytokines released from visceral WAT via HPV. Expression levels of inflammatory genes were lower in WAT of females than males, possibly due to estrogens' roles in suppressing inflammatory signaling in macrophages [52]. Our findings are consistent with previous studies showing rapid activation in lowgrade inflammation and increased macrophage content in WAT but not in the liver after 4 days of HFD feeding [53], and increased inflammation in WAT but not in skeletal muscle or liver after 3 days of HFD feeding [13]. Interestingly, although inflammation was not detected in WAT or muscle of PUFA males or in the liver of any HFD males, these tissues had reduced insulin sensitivity. This finding suggest that the initial stage of insulin resistance might be independent of inflammation, whereas chronic state of insulin resistance in established obesity might be mediated by macrophageinduced proinflammatory actions. Early-onset insulin resistance in the liver is more likely related to acute tissue lipid overload. SFA and MUFA males displayed hepatic insulin resistance and TG accumulation without elevated hepatic lipogenesis or inflammation, suggesting that the fatty liver vicious cycle involving lipid accumulation and insulin resistance had not yet started and might be reversible during this early phase of disease development.

Environmental factors, particularly availability of palatable and high-energy content food, have largely impacted on the prevalence of obesity and ensued metabolic syndrome. There is active search for alternative dietary fat due to lack of unambiguous data concerning optimal diets. Current findings extended the existing literature in two ways. First, MUFA-rich diet that has been deemed healthy mirrored similar lipogenic effects as SFA-rich diet and was predisposed to cause fatty liver in males. In contrast, PUFA-rich diet did not increase adiposity or liver TG content, denoting PUFA as a less lipogenic dietary fat. Metabolic advantages of PUFA-rich diet were also observed from a short-term feeding perspective, with PUFA males had relatively lower LDL-C levels and higher HDL/LDL ratios compared with SFA group, signifying PUFA as a CVD risk-free fatty acid. Therefore, beneficial effects of PUFA, but not MUFA, were corroborated in protection of hyperlipidemia, fatty liver, and low-grade inflammation. Second, sex differences exist during the initial stage of development of metabolic dysfunction. Short-term HFD feeding increased adiposity concomitant with metabolic defects, including liver lipid accumulation, tissue insulin resistance, rapid activation of low-grade inflammation in males. In contrast, female HFD groups had normal liver lipid content and maintained insulin sensitivity in most tissues without displaying tissue inflammation. Therefore, rapid occurrence of low-grade inflammation and insulin resistance were sex-specific and tissue-specific.

\section{Acknowledgements}

This study was supported by R15 NIDDK090823 (HS) and Madalene and George Shetler Diabetes Research Award (HS), Sigma Xi Grant-in-Aid of Research (MS), Summer Research Fellowship from the Endocrine Society (EGS), Miami University Dean's Scholarship (AJG), and Undergraduate Summer Scholarships (AJG and JDS).

\section{Disclosure}

The authors declare that they have no conflict interests. 


\section{References}

1. French SA, Story M, Jeffery RW (2001) Environmental influences on eating and physical activity. Annu Rev Publ Health 22: 309-335.

2. Wyatt SB, Winters KP, Dubbert PM (2006) Overweight and obesity: prevalence, consequences, and causes of a growing public health problem. Am JMed Sci 331: 166174.

3. Sims EAH (2001) Are there persons who are obese, but metabolically healthy? Metabolism 50: 1499-1504.

4. Miyazaki Y, Glass L, Triplitt C, Matsuda M, Cusi K, et al. (2001) Effect of rosiglitazone on glucose and non-esterified fatty acid metabolism in Type II diabetic patients. Diabetologia 44:2210-2219.

5. Carmona MC, Louche K, Nibbelink M, Prunet B, Bross A, et al. (2005) Fenofibrate prevents Rosiglitazoneinduced body weight gain in ob//ob mice. Int $J$ Obes Relat Metab Disord 29: 864-871.

6. Tiikkainen M, Häkkinen A-M, Korsheninnikova E, Nyman T, Mäkimattila S, et al. (2004) Effects of rosiglitazone and metformin on liver fat content, hepatic insulin resistance, insulin clearance, and gene expression in adipose tissue in patients with type 2 diabetes. Diabetes 53: 2169-2176.

7. Kolditz CI, Langin D (2010) Adipose tissue lipolysis. Curr Opin Clin Nutr Metab Care 13: 377-381.

8. Petersen KF, Dufour S, Befroy D, Lehrke M, Hendler RE, et al. (2005) Reversal of nonalcoholic hepatic steatosis, hepatic insulin resistance, and hyperglycemia by moderate weight reduction in patients with type 2 diabetes. Diabetes 54: 603-608.

9. Lara-Castro C, Garvey WT (2008) Intracellular lipid accumulation in liver and muscle and the insulin resistance syndrome. Endocrinol Metab Clin North Am 37: 841-856.

10. Weisberg SP, McCann D, Desai M, Rosenbaum M, Leibel RL, Ferrante AW (2003) Obesity is associated with macrophage accumulation in adipose tissue. $J$ Clin Invest 112: 1796-1808.

11. Xu H, Barnes GT, Yang Q, Tan G, Yang D, et al. (2003) Chronic inflammation in fat plays a crucial role in the development of obesity-related insulin resistance. $J$ Clin Invest 112: 1821-1830.

12 Kraegen EW, Clark PW, Jenkins AB, Daley EA, Chisholm DJ, et al. (1991) Development of muscle insulin resistance after liver insulin resistance in highfat-fed rats. Diabetes 40: 1397-1403.

13. Lee YS, Li P, Huh JY, Hwang IJ, Lu M, et al. (2011) Inflammation is necessary for long-term but not shortterm high-fat diet-induced insulin resistance. Diabetes 60: 2474-2483.

14. Kleemann R, van Erk M, Verschuren L, van den Hoek AM, Koek M, et al. (2010) Time-resolved and tissuespecific systems analysis of the pathogenesis of insulin resistance. PLoS One 5: e8817.

15. Gentile CL, Pagliassotti MJ (2008) The role of fatty acids in the development and progression of nonalcoholic fatty liver disease. J Nutr Biochem 19: 567-576.

16. Piers LS, Walker KZ, Stoney RM, Soares MJ, O’Dea K (2002) The influence of the type of dietary fat on postprandial fat oxidation rates: monounsaturated (olive oil) vs saturated fat (cream). Int J Obes Relat Metab Disord 26: 814-821.

17. Schroder H, Marrugat J, Vila J, Covas MI, Elosua R (2004) Adherence to the traditional mediterranean diet is inversely associated with body mass index and obesity in a Spanish population. J Nutr 134: 3355-3361.

18. Hill JO, Peters JC, Lin D, Yakubu F, Greene H, et al. (1993) Lipid accumulation and body fat distribution is influenced by type of dietary fat fed to rats. Int J Obes Relat Metab Disord 17: 223-236.

19. Wang H, Storlien LH, Huang XF (2002) Effects of dietary fat types on body fatness, leptin, and ARC leptin receptor, NPY, and AgRP mRNA expression. Am J Physiol Endocrinol Metab 282: E1352-1359.

20. Buettner R, Parhofer KG, Woenckhaus M, Wrede CE, Kunz-Schughart LA, Scholmerich J, et al. (2006) Defining high-fat-diet rat models: metabolic and molecular effects of different fat types. J Mol Endocrinol 36: 485-501.

21. Buckley JD, Howe PRC (2009) Anti-obesity effects of long-chain omega-3 polyunsaturated fatty acids. Obesity Rev 10: 648-659.

22. Krotkiewski M, Björntorp P, Sjöström L, Smith U (1983) Impact of obesity on metabolism in men and women. Importance of regional adipose tissue distribution. J Clin Invest 72: 1150-1162.

23. Laws A, Hoen HM, Selby JV, Saad MF, Haffner SM, et al. (1997) Differences in insulin suppression of free fatty acid levels by gender and glucose tolerance status. Relation to plasma triglyceride and apolipoprotein B concentrations. Arterioscler Thromb Vasc Biol 17: 64-71.

24. Frias JP, Macaraeg GB, Ofrecio J, Yu JG, Olefsky JM, et al. (2001) Decreased susceptibility to fatty acid-induced peripheral tissue insulin resistance in women. Diabetes 50: 1344-1350.

25. Shi H, Seeley RJ, Clegg DJ (2009) Sexual differences in the control of energy homeostasis. Front Neuroendocrinol 30: 396-404.

26. Livingstone C, Collison M (2002) Sex steroids and insulin resistance. Clin Sci (Lond) 102: 151-166.

27. Pettersson US, Waldén TB, Carlsson P-O, Jansson L, Phillipson M (2012) Female mice are protected against high-fat diet induced metabolic syndrome and increase the regulatory $\mathrm{T}$ cell population in adipose tissue. PLoS One 7: e46057. 
28. Foryst-Ludwig A, Kintscher U (2010) Metabolic impact of estrogen signalling through ERalpha and ERbeta. $J$ Steroid Biochem Mol Biol 122: 74-81.

29. Walmer DK, Wrona MA, Hughes CL, Nelson KG (1992) Lactoferrin expression in the mouse reproductive tract during the natural estrous cycle: correlation with circulating estradiol and progesterone. Endocrinology 131: 1458-1466.

30. Schwartz DM, Wolins NE (2007) A simple and rapid method to assay triacylglycerol in cells and tissues. $J$ Lipid Res 48: 2514-2520.

31. Leenen R, van der Kooy K, Meyboom S, Seidell JC, Deurenberg P, et al. (1993) Relative effects of weight loss and dietary fat modification on serum lipid levels in the dietary treatment of obesity. J Lipid Res 34: 21832191.

32. Maehira F, Miyagi I, Eguchi Y (1990) Sex- and age-related variations in the in vitro heparin-releasable lipoprotein lipase from mononuclear leukocytes in blood. Biochim Biophys Acta 1042: 344-351.

33. Kushlan MC, Gollan JL, Ma WL, Ockner RK (1981) Sex differences in hepatic uptake of long chain fatty acids in single-pass perfused rat liver. J Lipid Res 22: 431-436.

34. Mittendorfer B, Patterson BW, Klein S (2003) Effect of sex and obesity on basal VLDL-triacylglycerol kinetics. Am J Clin Nutr 77: 573-579.

35. Ma PT, Yamamoto T, Goldstein JL, Brown MS (1986) Increased mRNA for low density lipoprotein receptor in livers of rabbits treated with 17 alpha-ethinyl estradiol. Proc Natl Acad Sci U S A 83: 792-796.

36. Tilly-Kiesi M, Lichtenstein AH, Joven J, Vilella E, Cheung MC, et al. (1997) Impact of gender on the metabolism of apolipoprotein A-I in HDL subclasses LpAI and LpAI:AII in older subjects. Arterioscler Thromb Vasc Biol 17: 3513-3518.

37. Samaras K, Hayward CS, Sullivan D, Kelly RP, Campbell LV (1999) Effects of postmenopausal hormone replacement therapy on central abdominal fat, glycemic control, lipid metabolism, and vascular factors in type 2 diabetes: a prospective study. Diabetes Care 22: 1401-1407.

38. Clifton PM, Nestel PJ (1992) Influence of gender, body mass index, and age on response of plasma lipids to dietary fat plus cholesterol. Arterioscler Thromb Vasc Biol 12: 955-962.

39. Ginsberg HN, Karmally W, Siddiqui M, Holleran S, Tall AR, et al. (1995) Increases in dietary cholesterol are associated with modest increases in both LDL and HDL cholesterol in healthy young women. Arterioscler
Thromb Vasc Biol 15: 169-178.

40. Taskinen MR, Kuusi T (1986) High density lipoproteins in postprandial lipemia relation to sex and lipoprotein lipase activity. Atherosclerosis 59: 121-130.

41. Shulman GI (2000) Cellular mechanisms of insulin resistance. J Clin Invest 106: 171-176.

42. Rebrin K, Steil GM, Mittelman SD, Bergman RN (1996) Causal linkage between insulin suppression of lipolysis and suppression of liver glucose output in dogs. J Clin Invest 98: 741-749.

43. Baldeweg SE, Golay A, Natali A, Balkau B, Del Prato S, et al. (2000) Insulin resistance, lipid and fatty acid concentrations in 867 healthy Europeans. Eur J Clin Invest 30: 45-52.

44. Angulo, P (2002) Nonalcoholic fatty liver disease. $N$ Engl J Med 346: 1221-1231.

45. Oosterveer MH, van Dijk TH, Tietge UJF, Boer T, Havinga R, et al. (2009) High fat feeding induces hepatic fatty acid elongation in mice. PLoS One 4: e6066.

46. Liu H-Y, Hong T, Wen G-B, Han J, Zuo D, et al. (2009) Increased basal level of Akt-dependent insulin signaling may be responsible for the development of insulin resistance. Am J Physiol Endocrinol Metab 297: E898E906.

47. Muraki K, Okuya S, Tanizawa Y (2006) Estrogen receptor alpha regulates insulin sensitivity through IRS-1 tyrosine phosphorylation in mature 3T3-L1 adipocytes. Endocr J 53: 841-851.

48. Koricanac G, Milosavljevic T, Stojiljkovic M, Zakula Z, Ribarac-Stepic N, et al. (2008) Insulin signaling in the liver and uterus of ovariectomized rats treated with estradiol. J Steroid Biochem Mol Biol 108: 109-116.

49. Kumagai S, Holmäng A, Björntorp P (1993) The effects of oestrogen and progesterone on insulin sensitivity in female rats. Acta Physiol Scand 149: 91-97.

50. Ordóñez P, Moreno M, Alonso A, Llaneza P, Díaz F, et al. (2008) 17 $\beta$-Estradiol and/or progesterone protect from insulin resistance in STZ-induced diabetic rats. $J$ Steroid Biochem Mol Biol 111: 287-294.

51. Boden G, Chen X, Ruiz J, White JV, Rossetti L (1994) Mechanisms of fatty acid-induced inhibition of glucose uptake. J Clin Invest 93: 2438-2446.

52. Ghisletti S, Meda C, Maggi A, Vegeto E (2005) 17betaestradiol inhibits inflammatory gene expression by controlling NF-kappaB intracellular localization. Mol Cell Biol 25: 2957-2968.

53. Ji Y, Sun S, Xia S, Yang L, Li X, et al. (2012) Short term high fat diet challenge promotes alternative macrophage polarization in adipose tissue via natural killer T cells and interleukin-4. J Biol Chem 287: 24378-24386. 